\title{
Splenic Artery Embolisation for the Emergency Treatment of Sinistral Portal Hypertension: A Systematic Review
}

\author{
Harriet Grout-Smith ${ }^{1 *} \odot \odot \quad$ Ozbil Dumenci ${ }^{1 *} \odot \odot$ N. Paul Tait ${ }^{2} \quad$ Ali Alsafi ${ }^{2, \odot}$
}

${ }^{1}$ Faculty of Medicine, Imperial College London, London, United Kingdom

2Department of Imaging, Hammersmith Hospital, Imperial College

Address for correspondence Ali Alsafi, FRCR, EBIR, FRCP, Department of Imaging, Hammersmith Hospital, Imperial College Healthcare NHS Trust, Du Cane Road, London W12 OHS, United Healthcare NHS Trust, London, United Kingdom Kingdom (e-mail: ali.alsafi03@alumni.imperial.ac.uk).

\begin{abstract}
Keywords

- sinistral portal hypertension

- splenic artery embolization

- variceal hemorrhage
\end{abstract}

\section{Introduction}

Sinistral portal hypertension (SPH), also commonly known as left-sided or segmental portal hypertension, is a rare but serious cause of upper gastrointestinal hemorrhage. ${ }^{1,2} \mathrm{SPH}$ occurs as a result of splenic venous occlusion and is most commonly

${ }^{*}$ These authors contributed equally to this work.

DOI https://doi.org/ $10.1055 / \mathrm{s}-0041-1730876$ ISSN 2457-0214 characterized by isolated gastric varices. ${ }^{1-4}$ This occurs in the absence of true portal hypertension and patients have preserved liver function. ${ }^{2,5}$ Several pathologies can result in splenic vein occlusion, including acute or chronic pancreatitis and extrinsic splenic vein compression. As most individuals with the condition are asymptomatic, the incidence of
(C) 2021. Indian Society of Vascular and Interventional Radiology. This is an open access article published by Thieme under the terms of the Creative Commons Attribution-NonDerivative-NonCommercial-License, permitting copying and reproduction so long as the original work is given appropriate credit. Contents may not be used for commercial purposes, or adapted, remixed, transformed or built upon. (https://creativecommons.org/licenses/by-nc-nd/4.0/).

Thieme Medical and Scientific Publishers Pvt. Ltd. A-12, 2nd Floor, Sector 2, Noida-201301 UP, India 
Table 1 A table to show the search terms used to perform our literature search

\begin{tabular}{|l|l|}
\hline Exposure & AND Intervention \\
\hline Sinistral & (Splenic arter* AND embol*) \\
Left side* & OR \\
Segmental & $($ Spleen arter* and embol*) \\
Pre hepatic & OR \\
Extra hepatic & (Splenic arter* AND inflow AND \\
Regional & control) \\
Splenoportal & OR \\
Localited & (Splenic arter* AND occlu*) \\
Compartmental & \\
Lineal & \\
Non cirrho* & \\
AND & \\
Portal hypertension & \\
AND & \\
Varices & \\
Varix & \\
Bleed* & \\
H?emorrhage & \\
Mele?na & \\
H?ematemesis & \\
H?ematochezia & \\
\hline
\end{tabular}

Abbreviation: NA, not available.

*Average for the whole cohort, not just the SAE patients.

SPH is widely thought to be underreported. ${ }^{2,5}$ However, Xie et al showed that SPH may affect up to $3 \%$ of patients undergoing imaging for acute pancreatitis. ${ }^{6}$

Upper gastrointestinal bleeding is experienced by $18-35 \%$ of patients with SPH. ${ }^{7,8}$ Splenectomy is the definitive treatment of symptomatic SPH patients, but it is associated with significant mortality and morbidity in the acute setting. ${ }^{8,9}$ Endoscopic techniques such as balloon tamponade, sclerotherapy, and band ligation may temporarily stop bleeding from varices, but have a high rate of failure. ${ }^{10-13}$ Other non-surgical treatments for variceal hemorrhage secondary to $\mathrm{SPH}$ include splenic vein recanalization and splenic artery embolisation (SAE) ${ }^{14}$ SAE reduces splenic inflow, thereby reducing prefusion pressure of the gastric varices, and reduces the risk of further hemorrhage. SAE has been used alone, or as a bridging measure to stabilize patients prior to emergency splenectomy. ${ }^{15,16}$ There have been various studies over the years comparing SAE to surgical and other non-surgical treatments for SPH, but the exact role of SAE remains to be fully established in this group of patients., ${ }^{5,12,13,17-21}$ In this systematic review, we investigate the efficacy and safety of SAE in managing refractory gastric variceal bleeding in patients with SPH.

\section{Methods}

Institutional review board approval is not required to conduct this type of study.

\section{Literature Search}

MEDLINE and Embase databases were searched up until 1st September 2020 for randomized controlled trials, pilot, cohort or case-control studies investigating the outcomes of SAE in patients with gastric variceal bleeding due to SPH.
Search terms included synonymous names for SPH, "gastric varices", "variceal hemorrhage" and "SAE" (displayed in - Table 1). The search algorithm retrieved 339 papers overall (see - Figure 1). After a title and abstract screen, 262 papers were excluded due to the type of procedure or indication for intervention, paediatric or non-human populations or study design. Upon performing a full text review of the remaining 16 papers, those with insufficient data regarding the procedural success, recurrence of variceal bleeding and post procedural complications were excluded. A total of 7 papers were included in the systematic review. The 7 articles included were published between 1981 and 2014. With the exception of one prospective observational study, all the remaining articles were retrospective observational studies.

\section{Outcomes}

The primary outcomes were technical and clinical success. These were defined as cessation of splenic arterial blood flow on completion angiography and cessation of variceal bleeding, respectively. Secondary outcomes were procedural complications and mortality to assess the safety of SAE. Peri-procedural complications were classified as minor or major according to the Society of Interventional Radiology criteria. $^{22}$

\section{Eligibility Criteria}

The titles and abstracts of the publications retrieved by the search were reviewed. Studies were excluded from further review if SPH was not the exposure of interest (e.g., cirrhotic portal hypertension, splenic artery aneurysm, thrombocytopenia and splenic trauma), intervention was not SAE, or the population was not human adults. Additionally, all case reports, review articles, letters to the editor and commentaries were excluded. We performed a full text review of the remaining studies. Studies assessing the efficacy and safety of SAE as a treatment for gastric variceal bleeding due to SPH were included.

\section{Data Extraction}

From each paper included in this study, we extracted details of the study design, population, exposure of interest, SAE and outcomes. Regarding the studies themselves, we extracted: the name of the first author, year of publication, study design and whether it was a single or multi-center study. In terms of the study population, we extracted: the number of participants, age range, gender and length of follow-up. For the exposure, we extracted the etiologies of SPH and the number of participants with acute bleeding. SAE data extracted were the number of SAE procedures, embolic agent(s) used, whether failed endoscopy preceded the SAE, whether participants had a splenectomy post-SAE. Lastly, we extracted the rate of technical success, recurrence of bleeding in the SAE group and control group if present, complications and mortality post-SAE.

\section{Data Analysis}

A meta-analysis was not performed due to heterogeneity of the studies. A qualitative analysis was therefore chosen. 


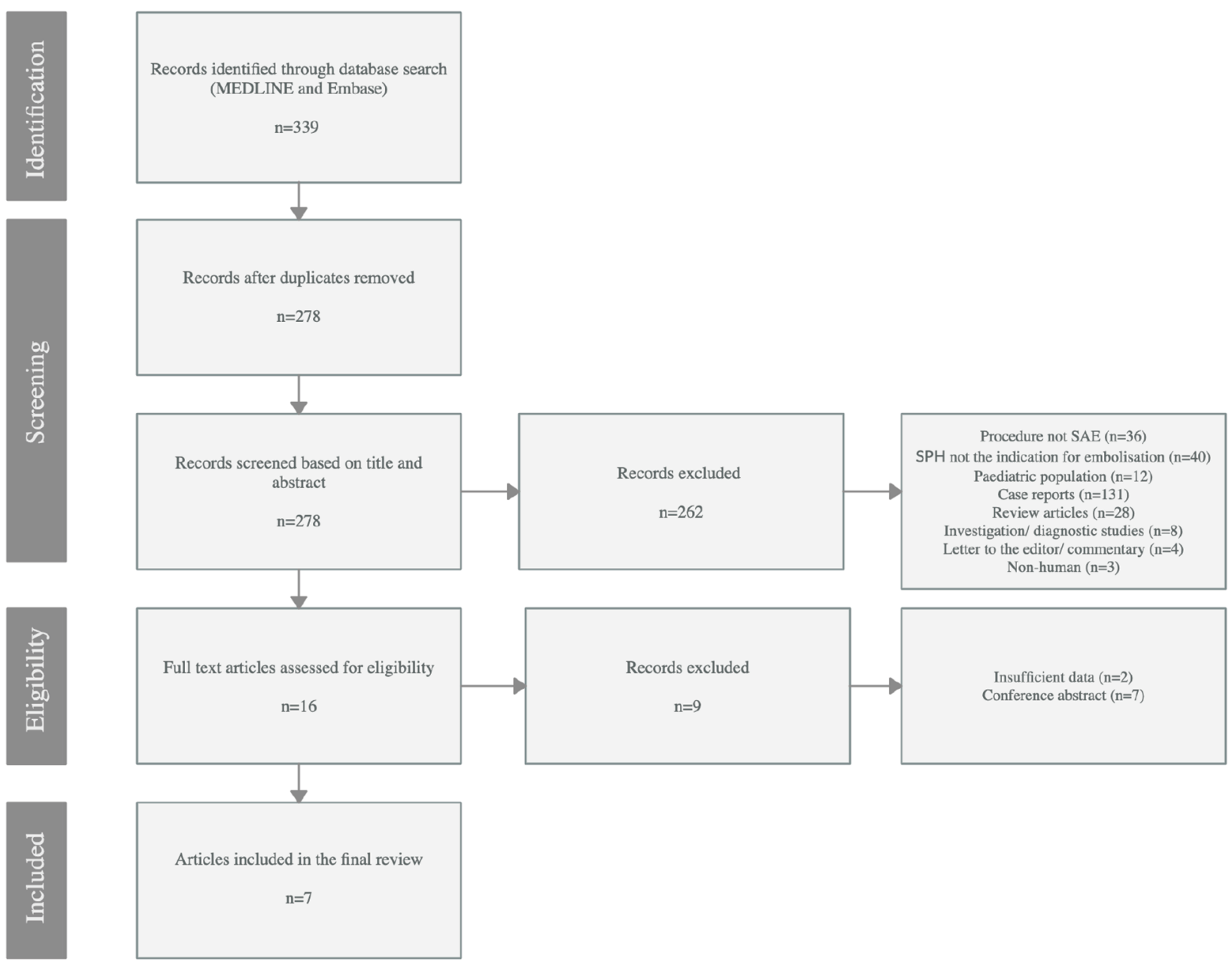

Fig. 1 Study selection flow chart.

A formal assessment of bias was not completed as all of the studies bar one were retrospective.

\section{Results}

The 7 articles included were published between 1981 and 2014. All of the articles were retrospective observational studies with the exception of one prospective observational study. The data extracted from these papers is summarized in - Table 2. The average number of patients included in each study was 16 , with an average of 4 embolisations to control variceal bleeding per study. Gender distribution was not included in one paper, ${ }^{20}$ however of the remaining studies, $74 \%$ of participants were male. Follow-up periods varied considerably between the different papers, with a range of $0-14$ years.

The details of patient baseline characteristics (summarized in - Table 3 ) are limited, providing little insight into their clinical status at the time of intervention. Two papers described their SAE patient population to be too unwell or prevented by underlying disease from having surgery ${ }^{12,17}$ Goldman et al reported that each patient received an average of 12 blood transfusions in the 5 days pre- and post-embolisation. They also clarified previous interventions, such as exploratory laparotomy in one patient, distal splenorenal shunts in 2 patients and portocaval shunts in 2 patients.

Embolisation techniques varied across the studies. Of the 29 SAE procedures, the embolisation technique / embolic agent was unknown in 7 patients. Polyvinyl alcohol particles (PVA) were used in 3 patients, and coils were used in 7 patients. Combined embolisation with PVA followed by coils was performed in 7 patients, 3 of which were completed at the same session and 4 completed 1 month apart. $N$-butyl cyanoacrylate (Bucrylate) was used in 4 patients, and a combination of an Amplatz occluder and gelfoam in one patient. Information on the proportion of the spleen embolised was limited. When using PVA particles as part of their combined embolisation, Wang et al aimed for embolisation of $60-70 \%$ of splenic volume.

The rate of technical success across all 7 studies was $100 \%$. Coil embolisation of the celiac trunk was performed in one patient due to tumor involvement of the proximal splenic artery and the presence of a pseudoaneurysm. ${ }^{13}$ There was no recurrence of gastric variceal bleeding during follow up, therefore, the overall clinical success rate was $100 \%$. Seven 
82 SAE for the Emergency Treatment of SPH Grout-Smith et al.

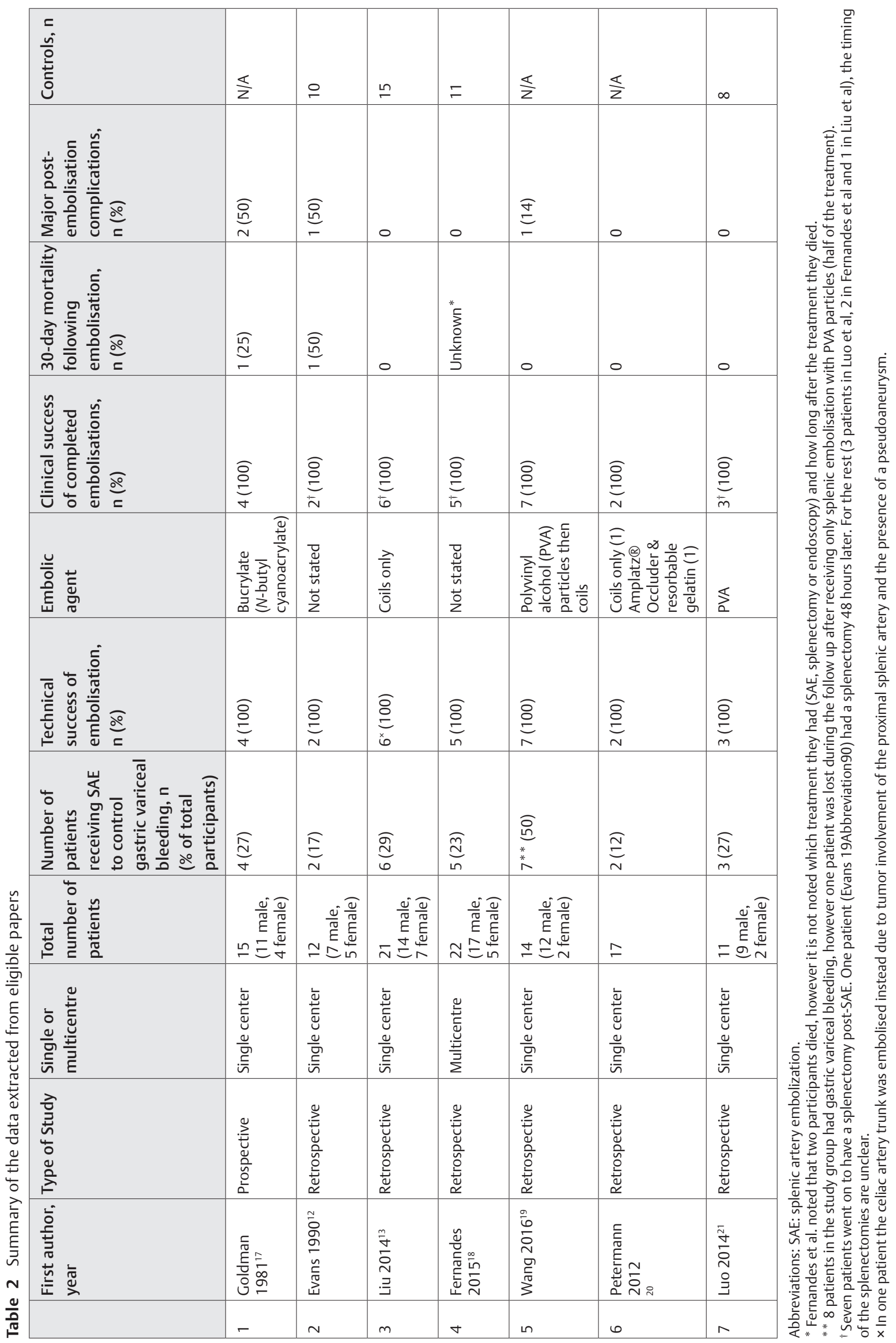


Table 3 Summary of patient characteristics from the selected papers

\begin{tabular}{|c|c|c|c|c|c|c|}
\hline & $\begin{array}{l}\text { First author, } \\
\text { year }\end{array}$ & $\begin{array}{l}\text { Number of } \\
\text { patients } \\
\text { receiving SAE }\end{array}$ & Gender & $\begin{array}{l}\text { Average } \\
\text { age }\end{array}$ & Etiology of SPH & $\begin{array}{l}\text { Number of patients } \\
\text { bleeding acutely }\end{array}$ \\
\hline 1 & $\begin{array}{l}\text { Goldman } \\
1981^{17}\end{array}$ & 4 & 4 males & 47 & $\begin{array}{l}\text { Acute and chronic pancreatitis (1) } \\
\text { Thrombosed splenorenal shunt ( } 2 \text { ) } \\
\text { Cirrhosis (1) }\end{array}$ & 4 \\
\hline 2 & Evans $1990^{12}$ & 2 & $\begin{array}{l}1 \text { male } \\
1 \text { female }\end{array}$ & 43 & $\begin{array}{l}\text { Pancreatic pseudocyst (1) } \\
\text { Pancreatic adenocarcinoma (1) }\end{array}$ & 2 \\
\hline 3 & Liu $2014^{13}$ & 6 & NA & $47^{*}$ & Advanced pancreatic tumors (6) & 6 \\
\hline 4 & $\begin{array}{l}\text { Fernandes } \\
2015^{18}\end{array}$ & 5 & NA & $60^{*}$ & NA & NA \\
\hline 5 & Wang $2016^{19}$ & 7 & NA & NA & $\begin{array}{l}\text { Acute pancreatitis (4) } \\
\text { Chronic pancreatitis (3) }\end{array}$ & 7 \\
\hline 6 & $\begin{array}{l}\text { Petermann } \\
2012^{20}\end{array}$ & 2 & NA & $61^{*}$ & $\begin{array}{l}\text { Pancreatitis (1) } \\
\text { Metastatic adenopathies (1) }\end{array}$ & 2 \\
\hline 7 & Luo $2014^{21}$ & 3 & $\begin{array}{l}2 \text { males } \\
1 \text { female }\end{array}$ & 45 & $\begin{array}{l}\text { Isolated pancreatic tuberculosis ( } 1 \text { ) } \\
\text { Chronic pancreatitis ( } 2 \text { ) }\end{array}$ & 3 \\
\hline
\end{tabular}

out of 29 patients (24\%) had splenectomies following SAE. The time that elapsed between SAE and splenectomy was unclear for 6 patients, but one splenectomy was performed 48 hours post-SAE. ${ }^{12}$

The most common minor complication reported was post-embolisation syndrome, characterized by left upper quadrant abdominal pain and fever. Nine patients (31\%) described by 3 articles experienced either pain, fever or both. 17,20,21 Wang et al noted that post-embolisation syndrome was the most frequent complication but did not quantify this. The remaining 13 patients (45\%) included in a further 3 articles experienced no minor complications. ${ }^{12,13,18}$ Other minor complications included 4 transient, reactive left pleural effusions, ${ }^{20} 3$ significantly raised platelet counts managed with aspirin and constipation in 5 patients. ${ }^{19}$ However, it is unclear whether these complications occurred in the patients of interest to this review as these papers included patients receiving SAE for other etiologies, such as hypersplenism.

The overall major complication and 30-day mortality rates were $14 \%$ and $8 \%$, respectively. There were 4 major procedural complications, 2 of which resulted in death. Two post-embolisation infections were observed. One infection occurred after PVA and coil embolisation and was due to splenic necrosis confirmed by CT. ${ }^{19}$ The second was a left upper quadrant abdominal abscess, which was drained 3 weeks post-SAE. ${ }^{17}$ This was following distal embolisation with N-butyl-cyano-acrylate.

The 2 deaths observed were in patients with multiple co-morbidities, however, both experienced SAE-related pulmonary complications and so were recorded as major procedural complications. One death was 3 weeks post-embolisation with N-butyl-cyano-acrylate and was attributed to a bleeding duodenal ulcer, hepatorenal syndrome and bronchopneumonia. ${ }^{17}$ This patient had received 33 units of blood during their admission prior to embolisation. Post-mortem examination showed no evidence of splenic infection or inflammation. Another death occurred 7 days after SAE in a patient with a background of pancreatic carcinoma, malignant ascites, pneumonia and a pleural effusion. ${ }^{12}$ Autopsy found a pulmonary embolus, a perforated gastric ulcer, and a pancreatic carcinoma occluding the splenic vein. Fernandes et al reported two deaths during the median follow up period of 24 months. However, it was unclear whether these patients had received SAE (this study also included endoscopic management and splenectomy) and how long after the procedure these deaths occurred.

\section{Discussion}

$\mathrm{SPH}$ is a rare but serious cause of upper gastrointestinal hemorrhage and is most commonly characterized by isolated gastric varices in the absence of true portal hypertension. Splenectomy is accepted as the definitive treatment of symptomatic SPH patients, but it is associated with significant mortality and morbidity in the acute setting. ${ }^{8,9}$ Splenic artery embolisation is a minimally invasive alternative that may be used alone or as an adjunct to surgery.

\section{Risk of Developing Varices in SPH}

The most common complication of SPH is bleeding, which occurs as a result of varices. ${ }^{3,7,8}$ Splenic vein occlusion results in increased venous pressure in local venous collaterals that act as venous outflow to the spleen such as the short gastric, gastroepiploic and coronary veins. The increased pressure in these venous collaterals results in dilatation of the veins in the gastric wall and can develop into gastric and sometimes oesophageal varices. ${ }^{3,23}$ Although common, not every individual with SPH is equally likely to develop varices. ${ }^{5}$ This is thought to be due to anatomic variations which may not allow the pressure diversion mechanisms to take place. Additionally, the risk of variceal bleeding also varies between individuals, most likely due to the degree of non-variceal collateral flow formation. ${ }^{5}$ 


\section{Treatment Options for SPH}

As variceal bleeding occurs in up to $35 \%$ of cases, control of bleeding is the most common aim in symptomatic patients in addition to removing the primary cause. ${ }^{7,8,11}$ Endoscopic measures to control bleeding in SPH patients include endoscopic sclerotherapy, balloon tamponade, band ligation and cyanoacrylate injection, which are associated with a high recurrence rate and are not without complication.,24 Splenectomy has widely been considered to be the definitive management in symptomatic SPH patients. ${ }^{25}$ This is thought to work by both decreasing the venous outflow from the collateral circulation as well as decompressing the existing collaterals, thus decreasing the risk of further hemorrhage. ${ }^{26-28}$ Splenectomy is associated with considerable morbidity and mortality in the acute setting. It carries a $10 \%$ risk of thromboembolic events, 1-2\% lifetime risk of post-splenectomy infection and up to $15 \%$ perioperative mortality, most commonly due to bleeding. ${ }^{29}$ Furthermore, the use of splenectomy in treating asymptomatic SPH patients prophylactically is difficult to justify, and watchful waiting is commonly the practice of choice in these patients. ${ }^{1,2}$

Splenic vein recanalization via a percutaneous transhepatic or splenic approach is another treatment option for isolated gastric varices secondary to $\mathrm{SPH} .{ }^{30} \mathrm{~A}$ retrospective analysis of 11 patients who underwent endovascular recanalization found a technical success rate of $73 \%$ (8/11) with no cases of rebleeding in those patients. ${ }^{21} 6$ patients had splenic vein stenosis rather than occlusion however. Post-procedural complications were observed in $25 \%$ of patients and in-stent stenosis occurred in $25 \%$ of patients at 9 and 15 months. The durability of splenic vein recanalization and stenting are drawbacks to the technique, particularly in benign disease.

Various studies have explored SAE as a viable treatment option for upper gastrointestinal hemorrhage secondary to $\mathrm{SPH}$. However, the use of SAE as a definitive treatment in place of splenectomy remains widely debated. ${ }^{5,15}$ SAE can cause serious complications, such as splenic abscess, pleural effusions, pneumonia, atelectasis, pulmonary emboli, and portal vein thrombosis. ${ }^{16}$ The disadvantage of SAE compared with splenectomy is the loss of opportunity to surgically treat pancreatic pathology, such as removing tumors or cysts, particularly as this is a major etiology of SPH in addition to leaving potentially ischemic tissue (spleen) in situ. ${ }^{10,31}$ Pancreatic pathology may cause local inflammation and adhesions, making splenectomy more technically difficult however. ${ }^{32}$ Advantages of SAE over splenectomy include being less invasive with shorter operative time and the ability to perform the procedure under local anesthesia. ${ }^{33}$ Currently, SAE is predominantly used as a temporising measure in patients who are unable to undergo splenectomy due to hemodynamic instability. ${ }^{12,34}$ However, the results of this systematic review show that SAE as a standalone treatment controlled gastric variceal bleeding in $100 \%$ of cases. Additionally, there was no rebleeding during follow up with 7 patients proceeding to splenectomy during this time. There was an overall major complication rate of $14 \%(4 / 29)$ and (excluding Fernandes et al) a 30 -day mortality rate of $8 \%(2 / 24)$. This is comparable to a previous review of 79 splenectomies for the treatment of SPH between 1969 and 1984, in which the clinical success rate was $92 \%$ and post-operative complication and mortality rates were $8 \% .^{26}$ The slightly higher rate of major complications in this review is to be expected as SAE is often performed in high-risk patients who are unlikely to survive an operation. ${ }^{12}$ Similar complication rates have been observed in SAE for the treatment of hypersplenism and blunt splenic trauma, varying between $4-13 \%$ in hypersplenism and averaging $20 \%$ in splenic trauma. ${ }^{35-37}$ SAE use in trauma is usually either proximal or superselective, which rarely result in complete splenic infarction. Furthermore, only partial embolization of the spleen is usually performed in hypersplenism. The safety and efficacy of the SAE for these two indications cannot, therefore, be extrapolated to SPH.

A variety of embolic agents may be used for splenic artery embolisation, including coils, vascular plugs, cyanoacrylate, particles and gelfoam. Particulate and glue embolic agents achieve distal embolisation, where splenic inflow is completely obliterated thereby reducing splenic outflow into the varices. ${ }^{39}$ On the other hand, proximal embolisation, using coils, reduces splenic inflow but does not obliterate it due to collaterals from the dorsal pancreatic and short gastric arteries. ${ }^{40}$ If patients continue to bleed following proximal embolisation, further embolisation may be difficult if not impossible. $^{41}$

Splenic artery embolisation is an effective treatment for gastric variceal bleeding secondary to sinistral portal hypertension. Further prospective studies are needed to ascertain optimal embolisation strategies and material and whether a staged approach (SAE followed by splenectomy) improves outcomes.

\section{Conflict of Interest}

None declared.

\section{References}

1 Wang L, Liu GJ, Chen YX, Dong HP, Wang LX. Sinistral portal hypertension: clinical features and surgical treatment of chronic splenic vein occlusion. Med Princ Pract 2012;21(1):20-23

2 Pereira P, Peixoto A. Left-Sided Portal Hypertension: A Clinical Challenge. GE Port J Gastroenterol 2015;22(6):231-233

3 Thompson RJ, Taylor MA, McKie LD, Diamond T. Sinistral portal hypertension. Ulster Med J 2006;75(3):175-177

4 Butler JR, Eckert GJ, Zyromski NJ, Leonardi MJ, Lillemoe KD, Howard TJ. Natural history of pancreatitis-induced splenic vein thrombosis: a systematic review and meta-analysis of its incidence and rate of gastrointestinal bleeding. HPB (Oxford) 2011;13(12):839-845

5 Köklü S, Çoban S, Yüksel O, Arhan M. Left-sided portal hypertension. Dig Dis Sci 2007;52(5):1141-1149

6 Xie CL, Wu CQ Chen Y, et al. Sinistral Portal Hypertension in Acute Pancreatitis: A Magnetic Resonance Imaging Study. Pancreas 2019;48(2):187-192

7 Pandey V, Patil M, Patel R, Chaubal A, Ingle M, Shukla A. Prevalence of splenic vein thrombosis and risk of gastrointestinal bleeding in chronic pancreatitis patients attending a tertiary hospital in western India. J Family Med Prim Care 2019;8(3):818-822

8 Weledji EP. Benefits and risks of splenectomy. Int J Surg 2014;12(2):113-119 
9 Sakorafas GH, Sarr MG, Farley DR, Farnell MB. The significance of sinistral portal hypertension complicating chronic pancreatitis. Am J Surg 2000;179(2):129-133

10 Weber SM, Rikkers LF. Splenic vein thrombosis and gastrointestinal bleeding in chronic pancreatitis. World J Surg 2003;27(11):1271-1274

11 Glynn MJ. Isolated splenic vein thrombosis. Arch Surg 1986;121(6):723-725

12 Evans GR, Yellin AE, Weaver FA, Stain SC. Sinistral (left-sided) portal hypertension. Am Surg 1990;56(12):758-763

13 Liu Q, Song Y, Xu X, Jin Z, Duan W, Zhou N. Management of bleeding gastric varices in patients with sinistral portal hypertension. Dig Dis Sci 2014;59(7):1625-1629

14 Van der Cruyssen F, Manzelli A. Splenic artery embolization: technically feasible but not necessarily advantageous. World J Emerg Surg 2016;11(1):47-61

15 Smith M, Ray CE. Splenic artery embolization as an adjunctive procedure for portal hypertension. Semin Intervent Radiol 2012;29(2):135-139

16 Guan Y, Ying Hu. Clinical Application of Partial Splenic Embolization. Sci World J 2014;2014

17 Martin L, Goldman, Philip K. Philip, Mohammad S. Sarraflzadeh, I. James Sarfeh, Atef A. Salam, John T. Galambos, et al.Intraarterial Tissue Adhesive for Medical Splenectomy in Humans. Radiology; $1981 ; 140$

18 Fernandes A, Almeida N, Ferreira AM, et al. Left-Sided Portal Hypertension: A Sinister Entity. GE Port J Gastroenterol 2015;22(6):234-239

19 Wang Q, Xiong B, Zheng C, Liang M, Han P. Splenic Arterial Embolization in the Treatment of Severe Portal Hypertension Due to Pancreatic Diseases: The Primary Experience in 14 Patients. Cardiovasc Intervent Radiol 2016;39(3):353-358

20 Petermann A, Chabrot P, Cassagnes L, et al. Hypersplenism due to portal hypertension: retrospective evaluation of 17 patients treated by splenic embolization. Diagn Interv Imaging 2012;93(1):30-36

21 Luo X, Nie L, Wang Z, Tsauo J, Tang C, Li X. Transjugular endovascular recanalization of splenic vein in patients with regional portal hypertension complicated by gastrointestinal bleeding. Cardiovasc Intervent Radiol 2014;37(1):108-113

22 Sacks D, McClenny TE, Cardella JF, Lewis CA. Society of Interventional Radiology clinical practice guidelines. J Vasc Interv Radiol 2003;14(9 Pt 2) :S199-S202

23 Kokabi N, Lee E, Echevarria C, Loh C, Kee S. Sinistral portal hypertension: presentation, radiological findings, and treatment options - a case report. J Radiol Case Rep 2010;4(10):14-20

24 Roesch W, Rexroth G. Pulmonary, cerebral and coronary emboli during bucrylate injection of bleeding fundic varices. Endoscopy 1998;30(8):S89-S90
25 Thavanathan J, Heughan C, Cummings TM. Splenic vein thrombosis as a cause of variceal bleeding. Can J Surg 1992;35(6):649-652

26 Moossa AR, Gadd MA. Isolated splenic vein thrombosis. World J Surg 1985;9(3):384-390

27 Warshaw AL, Jin GL, Ottinger LW. Recognition and clinical implications of mesenteric and portal vein obstruction in chronic pancreatitis. Arch Surg 1987;122(4):410-415

28 Salam AA, Warren WD, Tyras DH. Splenic vein thrombosis: a diagnosable and curable form of portal hypertension. Surgery 1973;74(6):961-972

29 Clarke PJ, Morris PJ, Section 43.1: Surgery of the Spleen. In: Morris PJ, Wood WC, editors. Oxford Textbook of Surgery. USA: Oxford University Press,; 2000

30 Stein M, Link DP. Symptomatic spleno-mesenteric-portal venous thrombosis: recanalization and reconstruction with endovascular stents. J Vasc Interv Radiol 1999;10(3):363-371

31 Lankisch PG. The spleen in inflammatory pancreatic disease. Gastroenterology 1990;98(2):509-516

32 Crary SE, Buchanan GR. Vascular complications after splenectomy for hematologic disorders. Blood 2009;114(14):2861-2868

33 CIRSE 2014. Cardiovasc Intervent Radiol 2014;37:83-373

34 Fujitani RM, Johs SM, Cobb SR, Mehringer CM, White RA, Klein SR. Preoperative splenic artery occlusion as an adjunct for high risk splenectomy. Am Surg 1988;54(10):602-608

35 Hadduck TA, McWilliams JP. Partial splenic artery embolization in cirrhotic patients. World J Radiol 2014;6(5):160-168

36 Koconis KG, Singh H, Soares G. Partial splenic embolization in the treatment of patients with portal hypertension: a review of the english language literature. J Vasc Interv Radiol 2007;18(4):463-481

37 Rong JJ, Liu D, Liang M, et al. The impacts of different embolization techniques on splenic artery embolization for blunt splenic injury: a systematic review and meta-analysis. Mil Med Res 2017;4:17

38 Ekeh AP, Khalaf S, Ilyas S, Kauffman S, Walusimbi M, McCarthy MC. Complications arising from splenic artery embolization: a review of an 11-year experience. Am J Surg 2013;205(3):250-254

39 Coldwell DM, Stokes KR, Yakes WF. Embolotherapy: agents, clinical applications, and techniques. Radiographics 1994;14(3):623-643, quiz 645-646

40 Hoppe H, Kos S. Splenic Artery Embolization: Proximal or Distal? Endovascular Today 2018;17:73-76

41 Imbrogno BF, Ray CE. Splenic artery embolization in blunt trauma. Semin Intervent Radiol 2012;29(2):147-149 